\title{
Fetal Sex-Dependent Associations Between Gestational Hormone Concentrations and Adverse Birth Outcomes: A Cohort Study
}

\author{
Amber L Cathey \\ University of Michigan \\ Deborah J Watkins \\ University of Michigan \\ Zaira Y Rosario \\ Universidad de Puerto Rico \\ Carmen M Vélez Vega \\ Universidad de Puerto Rico \\ Bhramar Mukherjee \\ University of Michigan \\ Marie S O'Neill \\ University of Michigan \\ Rita Loch-Caruso \\ University of Michigan \\ Akram N Alshawabkeh \\ Northeastern University \\ José $\mathrm{F}$ Cordero \\ University of Georgia \\ John D Meeker ( $\nabla$ meekerj@umich.edu ) \\ University of Michigan https://orcid.org/0000-0001-8357-5085
}

\section{Research}

Keywords: pregnancy, gestational age, preterm birth, corticotropin releasing hormone, preeclampsia, progesterone, birth cohort

Posted Date: August 20th, 2020

DOI: https://doi.org/10.21203/rs.3.rs-60256/v1

License: (c) (i) This work is licensed under a Creative Commons Attribution 4.0 International License. Read Full License 


\section{Abstract}

Background: Adverse birth outcomes remain significant public health problems that can have long-lasting impacts on mother and child. Understanding biological mechanisms underlying these outcomes, including altered endocrine function, can inform prevention efforts. Thus, we aimed to explore associations between repeated gestational hormone measurements and birth outcomes. Secondarily, we assessed impacts of fetal sex and timing of hormone measurement on these associations.

Methods: We explored associations between repeated gestational hormone measurements and birth outcomes among 976 women in PROTECT, a longitudinal prospective birth cohort in northern Puerto Rico. Birth outcomes assessed included preterm and spontaneous preterm birth (PTB), preeclampsia, gestational diabetes mellitus (GDM), small/large for gestational age (SGA, LGA), birth weight z-score, and gestational age at birth. Multivariate logistic and linear regressions were fit using pregnancy average concentrations of hormones. We also conducted sensitivity analyses assessing impacts of fetal sex and timing of hormone measurement on observed associations.

Results: Among male fetuses, spontaneous PTB was associated with increased average corticotropin releasing hormone (CRH) (OR: 2.50, 95\% Cl: 1.19, 5.24), increased total triiodothyronine (T3) (OR: 1.80, 95\% Cl: 1.02, 3.16) and decreased testosterone (OR: $0.34,95 \% \mathrm{Cl}: 0.15,0.74)$. Odds of GDM increased with average free thyroxine (fT4) (OR: $2.80,95 \% \mathrm{Cl}: 1.06,7.41)$, and decreased with average testosterone (OR: $0.23,95 \% \mathrm{Cl}: 0.06,0.86)$. Progesterone/estriol ratio was inversely associated with birth weight zscore (b: $-0.14,95 \% \mathrm{Cl}:-0.27,-0.01)$ and gestational age (b: -0.39 weeks, $95 \% \mathrm{Cl}:-0.66,-0.12)$, and positively associated with odds of SGA (OR: $2.08,95 \% \mathrm{Cl}: 1.36,3.19)$. Among females, birth weight z-score was inversely associated with progesterone (b: $-0.17,95 \% \mathrm{Cl}:-0.31,-0.02)$ and total thyroxine (T4) (b: $-0.16,95 \% \mathrm{Cl}:-0.30,-0.02)$, and GDM was inversely associated with progesterone/estriol (OR: 0.34, 95\% Cl: 0.12, 0.99).

Conclusions: Associations between hormones and birth outcomes vary based on timing of hormone measurement and fetal sex. Future studies are needed to understand mechanisms involved in adverse birth outcomes and fetal sex differences.

\section{Plain English Summary}

A woman's body undergoes many changes during pregnancy, including fluctuations in hormone levels that are required for a healthy pregnancy. Occurrence of adverse birth outcomes, such as preterm birth, could be affected by abnormal changes in hormone levels. In this study, we measured hormones in 976 pregnant women to see if they were associated with the occurrence of adverse birth outcomes. We found that several hormones were associated with increased risk for adverse birth outcomes, including progesterone, which is important for the mother's immune system and for preventing contractions, and thyroid hormones. We also analyzed data separately for women carrying male versus female babies, since hormone levels in the mother can be affected by hormones from the baby. We found that male babies were more sensitive to changes in hormones. Among mothers carrying a male baby, changes in hormone levels were associated with increased risk of preterm birth, having an unusually small baby, and gestational diabetes. In conclusion, changes in hormone levels during pregnancy may be able to predict risk of adverse birth outcomes, and women carrying male babies may be more sensitive to changes in hormone levels and be at higher risk for experiencing adverse birth outcomes.

\section{Background}

Preterm birth (PTB) affects approximately $11 \%$ of live births [1] and is the leading cause of neonatal mortality worldwide [2]. Infants born preterm are at increased risk for adverse health outcomes later in life including reduced renal function [3], visual and neurodevelopmental impairments [4], cerebral palsy [5], and reduced myocardial function [6]. Despite being a common and significant public health problem, the causes of PTB are complex and largely unknown. Preeclampsia, a hypertensive disorder of pregnancy, and gestational diabetes mellitus (GDM), a disease of reduced insulin sensitivity and elevated glucose levels unique to gestation, are even more poorly understood and are associated with adverse health outcomes for the fetus later in life [7,8]. Mothers who experience these pregnancy complications are at greater risk for developing end-stage kidney disease [9], cerebrovascular disease [10], and type 2 diabetes [11]. 
During pregnancy, the maternal and fetal endocrine milieus change and interact in unique ways at different points throughout gestation. Progesterone participates in a myriad of pregnancy-related physiological changes, and the complexity of its roles is reflected by the mixed efficacy of progesterone therapy as a preventative measure for preterm birth [12]. Estrogens are responsible for uterine maintenance and they increase expression of oxytocin receptors and gap junctions that are necessary for uterine contractions to occur [13]. Through pregnancy, progesterone maintains uterine quiescence and keeps contractile effects of estrogens in check [12]. Previous studies have demonstrated associations between clinical hyper- and hypothyroidism with adverse birth outcomes [14-17], but much less is known about subclinical thyroid disruption and pregnancy outcomes. Thus, endocrine function and related disruptions must be a focal point in the study of adverse birth outcomes.

Despite the importance of endocrine regulation for ensuring a healthy pregnancy, few large epidemiological studies exist that assess a wide array of hormone concentrations and pregnancy outcomes that could inform understanding of the biological origins of adverse birth outcomes. The majority of existing research focuses on one hormone or one class of hormones (e.g., exclusively studying steroid or thyroid hormones), which makes it challenging to gain a broad understanding of the endocrine pathways implicated in the onset of these birth outcomes [18-20]. The spontaneous subtype of PTB, in particular, has not been well studied, and current research on the relatively rare outcomes of preeclampsia and GDM is sparse [21-23]. Importantly, few previous studies have investigated hormone concentrations at more than one time point during gestation, nor have they assessed the impact of fetal sex on these associations.

The Puerto Rico Testsite for Exploring Contamination Threats (PROTECT) birth cohort was originally established to study environmental contaminants in relation to PTB in Puerto Rico. At the initiation of the PROTECT study, the rate of PTB in Puerto Rico was close to $18 \%$, one of the highest rates in the developed world [24]. Because endocrine disruption is proposed as a biological mechanism by which environmental exposures may interfere with gestation and labor, the aim of this study was to investigate associations between various hormone concentrations, measured at two time points during gestation, and adverse birth outcomes in the PROTECT birth cohort and how those associations may differ by fetal sexes.

\section{Methods}

\section{Study Population}

Pregnant women were recruited into the PROTECT birth cohort between 2012 and 2017 at 14 \pm 2 weeks' gestation from seven hospitals and prenatal clinics in the northern karst region of Puerto Rico. Study design and recruitment protocols have been described elsewhere [25]. Briefly, women were excluded from the study if they were younger than 18 years or older than 40 years, had their first clinic visit after their 20th week of pregnancy, had taken oral contraceptives within 3 months of getting pregnant, had used in vitro fertilization to get pregnant, or had known preexisting medical or obstetric conditions. Demographic and other self-reported health information was provided at the first clinic visit. Women were also excluded from the study if they did not have data on at least one exposure-outcome pair, resulting in a final sample size of 976 women. This study was approved by the research and ethics committees of the University of Michigan School of Public Health, University of Puerto Rico, Northeastern University, and participating hospitals and clinics. All study participants provided full informed consent prior to participation.

\section{Hormone Measurements}

All participating women provided serum samples at their first and third clinic visits, aligning with median 18 (16-20) and 26 (24-28) weeks' gestation. All serum samples collected were analyzed at the Central Ligand Assay Satellite Services (CLASS) laboratory in the Department of Epidemiology at the University of Michigan School of Public Health. Progesterone (Siemens, Cat\# 1586287) [26], sex hormone binding globulin (SHBG, Siemens, Cat\# 6520781) [27], testosterone (Siemens, Cat\# 5476206) [28], total triiodothyronine (T3, Siemens, Cat\# 8427516) [29], total thyroxine (T4, Siemens, Cat\# 9236439) [30], free thyroxine (fT4, Siemens, Cat\# 6490106) [31] and thyroid-stimulating hormone (TSH, Siemens, Cat\# 8700387) [32] were measured using a chemiluminescence immunoassay. Estriol (DiaMetra, Cat\# DKO019) [33] and corticotropin releasing hormone (CRH, LifeSpan, Cat\# LS-F5352) [34] were measured using an enzyme immunoassay. Some hormone concentrations were not available for all participants due to sample volume limitations. The ratios of progesterone to estriol (Prog/E3) and T3 to T4 (T3/T4) were assessed in addition to measured hormones because of previous research indicates that the ratios may be better indices of

Page $3 / 20$ 
adverse pregnancy outcomes than single hormone measurements $[19,35,36]$. All hormone concentrations below the limit of detection (LOD) were replaced by the LOD divided by the square root of two.

\section{Birth Outcome Assessment}

Based on recommendations from the American College of Obstetricians and Gynecologists, self-reported date of the last menstrual period was collected at the first study visit and used in combination with early ultrasound measurements to determine gestational age at birth [37]. PTB was defined as delivery before 37 weeks gestation. We also assessed spontaneous PTB, defined as PTB presenting with premature rupture of membranes, spontaneous preterm labor, or both [38]. Preeclampsia and GDM cases were determined based on diagnosis in the medical record by an attending physician. We calculated birth weight zscores based on fetal sex and gestational age using widely accepted international standards [39]. Those born with a birth weight $<10$ th percentile were considered small for gestational age (SGA), and those born with a birth weight > 90th percentile were considered large for gestational age (LGA).

\section{Statistical Methods}

Distributions of demographic, health, and pregnancy characteristics were calculated. Summary measures of gestational hormone concentrations were assessed using arithmetic means of all available concentrations for each study participant, or geometric means for log-normally distributed hormones. Distributions of hormone concentrations were also assessed individually at each study visit. Univariate linear models were used to test for significant differences between hormone concentrations at each study visit. Intraclass correlation coefficients (ICCs) were also used to assess between- and withinindividual variability of hormone concentrations across study visits. Trending changes in hormone concentrations through pregnancy were plotted comparing cases to controls for binary birth outcomes and stratified by fetal sex.

Associations between gestational average hormone concentrations and binary birth outcomes were assessed using multiple logistic regression models. Multiple linear regression models were used for continuous birth outcomes. All models adjusted for categorical forms of maternal age and maternal education. Further covariate adjustment differed between birth outcomes based on a priori knowledge and inclusion of the covariate impacting the hormone effect estimate by at least $10 \%$. Models for PTB and spontaneous PTB further adjusted for marital status and exposure to environmental tobacco smoke (ETS). Models for GDM further adjusted for ETS and alcohol use. SGA and LGA models further adjusted for smoking habits. Gestational age models further adjusted for martial status, ETS, alcohol use, and pre-pregnancy BMI. Finally, preeclampsia and birth weight z-score models further adjusted for pre-pregnancy BMI. All models assessing testosterone also included SHBG to adjust for bound testosterone.

To investigate whether fetal sex or the timing of hormone concentration measurement had a significant impact on hormone associations with birth outcomes, we utilized indicator variables for fetal sex and study visit and included interaction terms between each indicator variable and hormone concentration in final models. For example, to obtain the association between gestational average $\mathrm{CRH}$ concentration and PTB among women carrying female fetuses, an interaction term between $\mathrm{CRH}$ and a fetal sex indicator variable which equals 0 when fetal sex is female was used in the model. We can then interpret the beta coefficient for the $\mathrm{CRH}$ term in this equation as the association between gestational average $\mathrm{CRH}$ and PTB among women carrying females. The same approach was used to assess the effects of study visit timing on hormone associations independent of fetal sex (interaction between hormone and study visit indicator variable), and fetal sex and study visit timing simultaneously (models included two interaction terms: one between hormone and fetal sex indicator, the second between hormone and study visit indicator).

\section{Results}

Demographics of the study population are shown in Table 1. The majority of mothers were under the age of $30(67.1 \%)$ [median(IQR): $27(23,31)$ ], had at least some college education (79\%), were employed $(63 \%)$, had an annual household income under $\$ 30,000$ (63.1\%), were married (53.1\%), had never smoked $(86 \%)$ or been exposed to environmental tobacco smoke (88.7\%), did not drink alcohol during pregnancy (93.6\%), had given birth to less than 2 previous children (86.9\%), and had a prepregnancy BMI of less than 25 (56.1\%) [median(IQR): $24.1(21.4,28.1)$ ]. 
Maternal demographic characteristics of the study population ( $\mathrm{N}$ $=976$ )

\begin{tabular}{|c|c|}
\hline & $N(\%)$ \\
\hline \multicolumn{2}{|l|}{ Maternal Age (years) } \\
\hline $18-24$ & $354(36.3 \%)$ \\
\hline $25-29$ & $301(30.8 \%)$ \\
\hline $30-34$ & $206(21.1 \%)$ \\
\hline $35-41$ & $115(11.8 \%)$ \\
\hline Missing & $0(0 \%)$ \\
\hline \multicolumn{2}{|l|}{ Maternal Education } \\
\hline GED or less & $203(21 \%)$ \\
\hline Some College & $331(34.2 \%)$ \\
\hline Bachelors or Higher & $433(44.8 \%)$ \\
\hline Missing & $9(0.9 \%)$ \\
\hline \multicolumn{2}{|l|}{ Employment Status } \\
\hline No & $357(37 \%)$ \\
\hline Yes & $608(63 \%)$ \\
\hline Missing & $11(1.1 \%)$ \\
\hline \multicolumn{2}{|c|}{ Annual Household Income } \\
\hline$<10 \mathrm{k}$ & 269 (31.6\%) \\
\hline $10 k-<30 k$ & $268(31.5 \%)$ \\
\hline $30 k-50 k$ & $203(23.8 \%)$ \\
\hline$>=50 \mathrm{k}$ & $112(13.1 \%)$ \\
\hline Missing & $124(12.7 \%)$ \\
\hline \multicolumn{2}{|l|}{ Marital Status } \\
\hline Single & $197(20.4 \%)$ \\
\hline Married & $521(53.9 \%)$ \\
\hline Cohabitating & 249 (25.7\%) \\
\hline Missing & $9(0.9 \%)$ \\
\hline \multicolumn{2}{|l|}{ Smoking Status } \\
\hline Never & $833(86 \%)$ \\
\hline Ever & $121(12.5 \%)$ \\
\hline Current & $15(1.55 \%)$ \\
\hline Missing & $7(0.7 \%)$ \\
\hline
\end{tabular}




\begin{tabular}{|ll|}
\hline & N (\%) \\
\hline Never & $808(88.7 \%)$ \\
\hline 1 Hour or less & $40(4.39 \%)$ \\
\hline$>1$ Hour & $63(6.92 \%)$ \\
\hline Missing & $65(6.7 \%)$ \\
\hline Alcohol Use & \\
\hline Never & $504(52.2 \%)$ \\
\hline Yes, before Pregnancy & $400(41.4 \%)$ \\
\hline Yes, currently & $62(6.42 \%)$ \\
\hline Missing & $10(1.0 \%)$ \\
\hline Number of Previous Children & \\
\hline 0 & $355(42.7 \%)$ \\
\hline 1 & $367(44.2 \%)$ \\
\hline 2 to 5 & $109(13.1 \%)$ \\
\hline Missing & $145(14.9 \%)$ \\
\hline Pre-Pregnancy BMl & \\
\hline$[0,25]$ & $520(56.1 \%)$ \\
\hline (25, 30] & $240(25.9 \%)$ \\
\hline Above 30 & $167(18 \%)$ \\
\hline Missing & $4902(52 \%)$ \\
\hline Fetal Sex & \\
\hline Female & \\
\hline Male & \\
\hline Missing & \\
\hline
\end{tabular}

Distributions of hormone concentrations are shown in Table 2. Most hormone concentrations were significantly different at 18 and 26 weeks gestation, with notable increases occurring with estriol (median 15.1 and $38.2 \mathrm{ng} / \mathrm{mL}$ at 18 and 26 weeks, respectively) and progesterone (median 39.3 and $73.5 \mathrm{ng} / \mathrm{mL}$ at 18 and 26 weeks, respectively). ICCs, which reflect the degree of correlation and agreement between measurements, for all other hormones ranged from 0.647 (T4) to 0.856 (testosterone). 
Table 2

Distributions of gestational average (GA) and visit specific hormone concentrations

\begin{tabular}{|c|c|c|c|c|c|c|c|c|c|c|c|c|c|c|}
\hline & & $\mathbf{N}$ & $\min$ & 25th & 50th & 75th & 90th & 95th & Max & $\begin{array}{l}\text { Geo. } \\
\text { Mean }\end{array}$ & $\begin{array}{l}\text { Geo. } \\
\text { Stdv }\end{array}$ & IQR & $\begin{array}{l}\text { Visit } \\
\text { P- } \\
\text { value* }\end{array}$ & $\begin{array}{l}\text { ICC } \\
(95 \% \\
\text { Cl) }\end{array}$ \\
\hline \multirow[t]{3}{*}{$\begin{array}{l}\mathrm{CRH} \\
(\mathrm{pg} / \mathrm{mL})\end{array}$} & $\mathrm{GA}$ & 976 & 3.50 & 15.4 & 43.2 & 86.3 & 118 & 148 & 243 & 35.7 & 2.77 & 70.9 & 0.914 & $\begin{array}{l}0.71 \\
(0.66 \\
0.74)\end{array}$ \\
\hline & $\begin{array}{l}\text { Visit } \\
1\end{array}$ & 818 & 3.50 & 15.1 & 37.6 & 84.3 & 121 & 156 & 254 & 34.4 & 2.89 & 69.2 & & \\
\hline & $\begin{array}{l}\text { Visit } \\
2\end{array}$ & 602 & 3.50 & 14.7 & 39.3 & 88.2 & 130 & 159 & 249 & 34.2 & 2.95 & 73.4 & & \\
\hline \multirow[t]{3}{*}{$\begin{array}{l}\text { Estriol } \\
(\mathrm{mg} / \mathrm{mL})\end{array}$} & $\mathrm{GA}$ & 971 & 0.74 & 15.6 & 23.1 & 33.0 & 44.7 & 57.5 & 265 & 22.7 & 1.80 & 17.4 & 0.000 & $\begin{array}{l}-0.22 \\
(-0.35 \\
-0.11)^{\prime}\end{array}$ \\
\hline & $\begin{array}{l}\text { Visit } \\
1\end{array}$ & 812 & 0.74 & 11.3 & 15.1 & 22.2 & 31.8 & 41.5 & 108 & 15.8 & 1.75 & 10.9 & & \\
\hline & $\begin{array}{l}\text { Visit } \\
2\end{array}$ & 600 & 6.90 & 29.3 & 38.2 & 50.5 & 64.4 & 74.6 & 265 & 38.7 & 1.55 & 21.2 & & \\
\hline \multirow[t]{3}{*}{$\begin{array}{l}\text { SHBG } \\
(\mathrm{pg} / \mathrm{mL})\end{array}$} & $\mathrm{GA}$ & 976 & 47.6 & 413 & 538 & 668 & 818 & 895 & 1404 & 522 & 1.45 & 254 & 0.000 & $\begin{array}{l}0.76 \\
(0.72, \\
0.79)\end{array}$ \\
\hline & $\begin{array}{l}\text { Visit } \\
1\end{array}$ & 820 & 47.6 & 389 & 516 & 630 & 775 & 850 & 1461 & 491 & 1.47 & 241 & & \\
\hline & $\begin{array}{l}\text { Visit } \\
2\end{array}$ & 602 & 123 & 434 & 566 & 723 & 898 & 979 & 1428 & 558 & 1.45 & 289 & & \\
\hline \multirow[t]{3}{*}{$\begin{array}{l}\text { Prog. } \\
\text { (ng/mL) }\end{array}$} & $\mathrm{GA}$ & 973 & 10.1 & 36.6 & 50.4 & 71.0 & 99.4 & 124 & 1037 & 51.8 & 1.68 & 34.5 & 0.000 & $\begin{array}{l}0.07 \\
(-0.04 \\
0.17)\end{array}$ \\
\hline & $\begin{array}{l}\text { Visit } \\
1\end{array}$ & 815 & 10.1 & 29.2 & 39.3 & 54.5 & 71.9 & 85.0 & 301 & 40.1 & 1.59 & 25.3 & & \\
\hline & $\begin{array}{l}\text { Visit } \\
2\end{array}$ & 601 & 19.4 & 51.2 & 73.5 & 104 & 146 & 179 & 1037 & 74.4 & 1.70 & 53.2 & & \\
\hline \multirow[t]{3}{*}{$\begin{array}{l}\text { TSH } \\
\text { (ulU/mL) }\end{array}$} & $\mathrm{GA}$ & 971 & 0.03 & 0.71 & 1.10 & 1.72 & 2.38 & 2.99 & 32.4 & 1.08 & 1.96 & 1.02 & 0.031 & $\begin{array}{l}0.72 \\
(0.67 \\
0.75)\end{array}$ \\
\hline & $\begin{array}{l}\text { Visit } \\
1\end{array}$ & 812 & 0.02 & 0.67 & 1.05 & 1.66 & 2.38 & 2.88 & 40.9 & 1.03 & 2.06 & 0.99 & & \\
\hline & $\begin{array}{l}\text { Visit } \\
2\end{array}$ & 600 & 0.11 & 0.72 & 1.15 & 1.75 & 2.43 & 3.23 & 25.7 & 1.12 & 1.96 & 1.03 & & \\
\hline \multirow[t]{3}{*}{$\begin{array}{l}\text { fT4 } \\
\text { (ng/dL) }\end{array}$} & $\mathrm{GA}$ & 976 & 0.11 & 1.09 & 1.62 & 2.02 & 2.32 & 2.50 & 8.35 & 1.41 & 1.68 & 0.93 & 0.452 & $\begin{array}{l}0.75 \\
(0.71 \\
0.79)\end{array}$ \\
\hline & $\begin{array}{l}\text { Visit } \\
1\end{array}$ & 818 & 0.11 & 1.03 & 1.57 & 2.01 & 2.30 & 2.48 & 8.35 & 1.34 & 1.84 & 0.98 & & \\
\hline & $\begin{array}{l}\text { Visit } \\
2\end{array}$ & 602 & 0.11 & 1.10 & 1.61 & 2.03 & 2.33 & 2.49 & 4.68 & 1.39 & 1.75 & 0.93 & & \\
\hline $\begin{array}{l}\text { T4 } \\
\text { (ug/dL) }\end{array}$ & $\mathrm{GA}$ & 975 & 0.35 & 0.89 & 1.00 & 1.10 & 1.21 & 1.28 & 1.72 & 0.99 & 1.19 & 0.21 & 0.000 & $\begin{array}{l}0.65 \\
(0.59 \\
0.69)\end{array}$ \\
\hline
\end{tabular}




\begin{tabular}{|c|c|c|c|c|c|c|c|c|c|c|c|c|c|c|}
\hline & & $\mathbf{N}$ & $\min$ & 25th & 50th & 75th & 90th & 95th & Max & $\begin{array}{l}\text { Geo. } \\
\text { Mean }\end{array}$ & $\begin{array}{l}\text { Geo. } \\
\text { Stdv }\end{array}$ & IQR & $\begin{array}{l}\text { Visit } \\
\text { P- } \\
\text { value* }\end{array}$ & $\begin{array}{l}\text { ICC } \\
(95 \% \\
\text { Cl) }\end{array}$ \\
\hline & $\begin{array}{l}\text { Visit } \\
1\end{array}$ & 818 & 0.35 & 0.90 & 1.01 & 1.12 & 1.21 & 1.28 & 1.72 & 1.00 & 1.19 & 0.22 & & \\
\hline & $\begin{array}{l}\text { Visit } \\
2\end{array}$ & 602 & 0.44 & 0.83 & 0.96 & 1.08 & 1.19 & 1.23 & 1.43 & 0.94 & 1.21 & 0.25 & & \\
\hline \multirow[t]{3}{*}{$\begin{array}{l}\text { T3 } \\
(\mathrm{mg} / \mathrm{mL})\end{array}$} & GA & 971 & 6.20 & 10.5 & 11.8 & 13.2 & 14.4 & 15.2 & 19.0 & 11.7 & 1.18 & 2.70 & 0.008 & $\begin{array}{l}0.72 \\
(0.67 \\
0.75)\end{array}$ \\
\hline & $\begin{array}{l}\text { Visit } \\
1\end{array}$ & 812 & 6.80 & 10.6 & 11.9 & 13.3 & 14.4 & 15.3 & 19.0 & 11.8 & 1.19 & 2.70 & & \\
\hline & $\begin{array}{l}\text { Visit } \\
2\end{array}$ & 600 & 5.30 & 10.3 & 11.6 & 13.0 & 14.2 & 14.9 & 20.6 & 11.5 & 1.19 & 2.75 & & \\
\hline \multirow[t]{3}{*}{$\begin{array}{l}\text { Test. } \\
(\mathrm{pg} / \mathrm{mL})\end{array}$} & $\mathrm{GA}$ & 973 & 2.80 & 53.0 & 107 & 557 & 819 & 992 & 2868 & 160 & 3.55 & 504 & 0.012 & $\begin{array}{l}0.86 \\
(0.83 \\
0.88)\end{array}$ \\
\hline & $\begin{array}{l}\text { Visit } \\
1\end{array}$ & 815 & 1.10 & 50.1 & 105 & 544 & 789 & 952 & 2500 & 156 & 3.66 & 493 & & \\
\hline & $\begin{array}{l}\text { Visit } \\
2\end{array}$ & 601 & 9.20 & 59.3 & 121 & 650 & 933 & 1092 & 3291 & 185 & 3.64 & 591 & & \\
\hline \multicolumn{15}{|c|}{$\begin{array}{l}\text { *P-value from a univariate linear model for association between hormone concentrations and study visit. Boldface } \mathrm{p} \text {-values } \\
\text { are }<0.05 \text {. }\end{array}$} \\
\hline
\end{tabular}

Distributions of birth outcomes are shown in Table 3. PTB and spontaneous PTB occurred in $9.9 \%$ and $5.8 \%$ of the study population, respectively. As expected, preeclampsia and GDM were less prevalent ( $2.9 \%$ and $1.9 \%$, respectively). Occurrences of SGA and LGA births were similar ( $8.9 \%$ and $9.6 \%$, respectively). Median gestational age of the study population was 39.1 weeks (IQR: 38.1-40). 
Table 3

Distributions of continuous and binary birth outcomes

\begin{tabular}{|c|c|c|c|c|c|c|c|}
\hline & Min & 10th & 25th & 50th & 75th & 90th & Max \\
\hline Gestational Age (wks) & 20.3 & 36.7 & 38.1 & 39.1 & 40 & 40.7 & 42.7 \\
\hline \multirow[t]{3}{*}{ Birth Weight Z-Score (ounces) } & -5.34 & -1.19 & -0.571 & -0.00005 & 0.707 & 1.25 & 9.70 \\
\hline & $(19.0)$ & $(91.0)$ & $(102)$ & $(113)$ & $(123)$ & (133) & $(224)$ \\
\hline & \multicolumn{7}{|l|}{$\mathbf{N}(\%)$} \\
\hline \multicolumn{8}{|l|}{ Preterm Birth } \\
\hline No & \multicolumn{7}{|c|}{$867(90.1 \%)$} \\
\hline Yes & \multicolumn{7}{|c|}{$95(9.88 \%)$} \\
\hline \multicolumn{8}{|l|}{ Spontaneous Preterm Birth } \\
\hline No & \multicolumn{7}{|c|}{$883(94.2 \%)$} \\
\hline Yes & \multicolumn{7}{|c|}{$54(5.76 \%)$} \\
\hline \multicolumn{8}{|l|}{ Preeclampsia } \\
\hline No & \multicolumn{7}{|c|}{$947(97.1 \%)$} \\
\hline Yes & \multicolumn{7}{|c|}{$28(2.87 \%)$} \\
\hline \multicolumn{8}{|l|}{ Gestational Diabetes } \\
\hline No & \multicolumn{7}{|c|}{$900(98.1 \%)$} \\
\hline Yes & \multicolumn{7}{|c|}{$17(1.85 \%)$} \\
\hline \multicolumn{8}{|l|}{ Small for Gestational Age } \\
\hline No & \multicolumn{7}{|c|}{$842(91.1 \%)$} \\
\hline Yes & \multicolumn{7}{|c|}{$82(8.87 \%)$} \\
\hline \multicolumn{8}{|l|}{ Large for Gestational Age } \\
\hline No & \multicolumn{7}{|c|}{$835(90.4 \%)$} \\
\hline Yes & \multicolumn{7}{|c|}{$89(9.63 \%)$} \\
\hline \multicolumn{8}{|c|}{$\begin{array}{l}\text { Additional File 1: Hormone concentrations between cases and controls for binary outcomes, comparing women carrying } \\
\text { females versus males. }\end{array}$} \\
\hline \multicolumn{8}{|c|}{$\begin{array}{l}\text { Solid lines are trends for cases, while dashed lines are trends for normal pregnancies. All red lines correspond to mothers } \\
\text { carrying a female fetus, and all blue lines correspond to mothers carrying a male fetus. Background dots represent cases for } \\
\text { each birth outcome. }\end{array}$} \\
\hline
\end{tabular}

Additional File 1 depicts the differences in hormone concentrations between cases and controls over the study period for each birth outcome, stratified by fetal sex. $\mathrm{CRH}$, progesterone, and T3 concentrations were higher across pregnancy among women presenting with PTB, spontaneous PTB, and GDM only when the fetal sex was male, with the difference in progesterone concentrations becoming minimal later in pregnancy. When mothers were carrying a female fetus, $\mathrm{CRH}$ concentrations among PTB and spontaneous PTB cases were lower than concentrations for control women, particularly later in pregnancy (around 26 weeks). Conversely, testosterone concentrations were higher among PTB, spontaneous PTB, and GDM cases when fetal sex was female compared to male across pregnancy. Among women with preeclampsia, those carrying a female fetus had lower concentrations of SHBG and progesterone but higher concentrations of TSH and testosterone compared to women carrying males across pregnancy. Among women with GDM, those carrying a male fetus had higher SHBG, progesterone, fT4, T4, and 
prog/e3 concentrations later in pregnancy relative to those carrying females. Among GDM cases, T3/T4 was higher earlier in pregnancy (around 18 weeks) when the fetal sex was male, but later in pregnancy (around 26 weeks) when fetal sex was female.

Associations between gestational average hormone concentrations and birth outcomes are shown in Fig. 1. PTB was not significantly associated with any hormone concentrations, however gestational age at birth was reduced by 1.81 ( $95 \% \mathrm{Cl}$ : 0.36 , 3.26), 1.78 (95\% Cl: $0.18,3.39)$ and 2.55 (95\% Cl: 1.16, 3.93) days with IQR increases in fT4, T4, and prog/e3, respectively. An IQR increase in fT4 was also associated with $1.57(95 \% \mathrm{Cl}: 1.11,2.24)$ times greater odds of spontaneous PTB, while an IQR increase in prog/e3 was also associated with $1.63(95 \% \mathrm{Cl}: 1.00,2.65)$ times greater odds of preeclampsia and $1.43(95 \% \mathrm{Cl}: 1.10,1.88)$ times greater odds of SGA. Increased progesterone was associated with both greater odds of SGA (OR: $1.47,95 \%$ Cl: 1.10, 1.95) and with lower birth weight z-score ( $\beta$ : $0.09,95 \% \mathrm{Cl}$ : $-0.19,0.00)$. Finally, the odds of GDM were reduced (OR: $0.37,95 \% \mathrm{Cl}: 0.13$, 1.01) with an IQR increase in testosterone concentration.

We also examined the differences in hormone associations with birth outcomes by fetal sex and the timing of hormone concentration measurement. Figure 2 shows the associations between gestational average hormone concentrations and birth outcomes, by fetal sex. Among women carrying a male fetus, the odds of PTB were significantly increased with IQR increases in CRH (OR: 1.87, 95\%Cl: 1.08, 3.24), estriol (OR: 1.48, 95\% Cl: 0.99, 2.20), progesterone (OR:1.60, 95\% Cl: 1.11, 2.29), and fT4 (OR: $1.48,95 \% \mathrm{Cl}: 1.00,2.20)$, whereas the odds of PTB were decreased with an IQR increase in testosterone (OR: 0.56, 95\% Cl: 0.31, 1.00). Similar results were found with spontaneous PTB, with the exception of estriol which showed a null association. Additionally, an IQR increase in T3 was associated with 1.80 (95\% Cl: 1.02, 3.16) times greater odds of spontaneous PTB among women carrying a male fetus. Similarly, gestational age at birth decreased by 2.88 (95\%Cl: 0.97, 4.79), 2.24 (95\% Cl: 0.26, 4.21), and $2.74(95 \% \mathrm{Cl}: 0.84,4.63)$ days with IQR increases in progesterone, fT4, and prog/e3, respectively, when fetal sex was male.

The odds of GDM increased with an IQR increase in fT4 (OR: 2.80, 95\% Cl: 1.06, 7.41) and decreased with an IQR increase in testosterone (OR: $0.23,95 \% \mathrm{Cl}: 0.06,0.86)$ when fetal sex was male. Odds of GDM also decreased with an IQR increase in prog/e3 (OR: 0.34, 95\% Cl: 0.12, 0.99) when fetal sex was female.

Increases in progesterone (OR: 1.50, 95\% Cl: 1.02, 2.21) and prog/e3 (OR: 2.08, 95\% Cl: 1.36, 3.19) were associated with increased odds of delivering an SGA male, but not female infant. Birth weight $z$-score was reduced with increasing concentrations of progesterone ( $\beta$ : $-0.17,95 \% \mathrm{Cl}:-0.31,-0.02)$ and $\mathrm{T} 4(\beta:-0.16,95 \% \mathrm{Cl}:-0.30,-0.02)$ among women carrying a female fetus, but only prog/e3 ( $\beta$ : $-0.14,95 \% \mathrm{Cl}:-0.27,-0.01)$ among women carrying a male fetus.

Some hormone relationships with birth outcomes differed when measured around 18 versus 26 weeks gestation (Fig. 3). Regardless of fetal sex, there were greater odds of spontaneous PTB with increasing progesterone concentrations around 26 weeks (OR: $2.12,95 \% \mathrm{Cl}: 1.26,3.55)$ and fT4 concentrations at both study visits (18wk OR: 1.60, 95\% Cl: 1.06, 2.41; 26wk OR: $1.73,95 \% \mathrm{Cl}: 1.00,2.97)$. Reductions in gestational age at birth were observed with increased concentrations of progesterone ( $\beta$ : -3.56 days, $95 \% \mathrm{Cl}:-5.51,-1.60)$, fT4 ( $\beta$ : -2.22 days, $95 \% \mathrm{Cl}:-3.87,-0.58)$, and T4 ( $\beta:-1.87$ days, $95 \% \mathrm{Cl}:-3.47,-0.27)$ around 18 weeks, and with prog/e3 at both study visits (18wk $\beta$ : -1.77 days, $95 \% \mathrm{Cl}:-3.20,-0.34 ; 26 w k$ : -1.98 days, $95 \% \mathrm{Cl}:-3.83,-0.12$ ).

Increases in TSH (OR: 2.18, 95\% Cl: 1.08, 4.40) and prog/e3 (OR: 1.78, 95\% Cl: 0.99, 3.19) at 26 weeks were associated with greater odds of preeclampsia, while SHBG at both time points was inversely associated with preeclampsia (18wk OR: $0.55,95 \%$ Cl: 0.31, 0.96; 26wk OR: 0.46, 95\% Cl: 0.22, 0.94). Increases in T3 (OR: 2.83, 95\% Cl: 1.09, 7.34) and T3/T4 (OR: 2.97, 95\% Cl:1.19, $7.43)$ at 18 weeks were associated with greater odds of GDM, while increases in estriol (OR: $5.95,95 \%$ Cl: $1.45,24.5)$ and progesterone (OR: $2.71,95 \% \mathrm{Cl}: 1.09,6.69)$ were associated with greater odds of GDM around 26 weeks.

Increased odds of SGA were observed with increasing progesterone concentrations around 18 weeks (OR: 1.53, 95\% Cl: 1.00, 2.34), and with increasing prog/e3 at both study visits (18wk OR: 1.77, 95\% Cl: 1.29, 2.43; 26wk OR: 1.53, 95\% Cl: 1.06, 2.19). Concordantly, increased estriol around 26 weeks ( $\beta$ : $0.21,95 \% \mathrm{Cl}: 0.00,0.42)$, and decreased prog/e3 around 18 weeks ( $\beta$ : -0.12 , $95 \% \mathrm{Cl}:-0.22,-0.03)$, were associated with increased birth weight $z$-score.

\section{Discussion}


We observed a range of significant associations between gestational hormone concentrations and adverse birth outcomes in a Puerto Rican birth cohort. Alterations of progesterone, estriol, and thyroid hormones were implicated in the occurrence of most birth outcomes assessed. Fetal sex differences were observed for many associations, with most significant results observed only when the fetus was male. Also, compared with hormone levels measured around 18 weeks' gestation, most of the strongest associations with birth outcomes were observed for hormone measures at around 26 weeks' gestation.

\section{PTB and Gestational Age}

We observed greater odds of PTB and spontaneous PTB with increasing progesterone concentrations (when fetal sex was male), but other studies demonstrating similar significant associations are lacking. One study observed progesterone concentrations measured between 28 and 32 weeks' gestation to be higher among women who delivered preterm compared to women who carried to full term [18]. We did observe higher progesterone concentrations among PTB cases when fetal sex was male, but only around 18 weeks' gestation. We also observed higher progesterone concentrations around 26 weeks among women who spontaneously delivered preterm compared to women who carried to term.

Progesterone concentrations rise steadily during pregnancy, contributing to uterine quiescence, downregulation of prostaglandin production, and immune tolerance of the fetus [40,41]. At the onset of labor in humans, progesterone concentrations do not notably decrease; rather, the body's response to progesterone is dampened. It is not clear exactly how this occurs, but possibilities include reduction in progesterone receptor expression, changes in receptor isoforms, and local progesterone metabolism [42]. As term approaches, the ratio of progesterone to estriol shifts to favor estrogens, with the functional decrease in progesterone driving initiation of labor [43]. The new dominance of estrogens promotes an increase in prostaglandin and oxytocin receptors and enzymes responsible for muscle contractions, which work together to help promote labor [44]. We observed a marginal positive association between odds of PTB and estriol concentrations (when fetal sex was male), but we also unexpectedly observed later gestational age at birth with higher concentrations of estriol at 26 weeks' gestation when the fetus was female.

The ratio of progesterone to estriol throughout pregnancy could be a better biomarker to study PTB because the onset of labor requires that estriol concentrations remain high and progesterone stimulation decreases. Previous work has shown that a ratio favoring estriol in mid-pregnancy [19] and at delivery [45] is associated with earlier time of labor. In contrast with those studies, we observed that a higher prog/e3 ratio was associated with reduced gestational age and increased odds of SGA. When study visits were assessed individually, we observed reduced odds of PTB with higher prog/e3 at 18 weeks, whereas the opposite association was observed at 26 weeks, although these results were not statistically significant. Interestingly, among women who delivered preterm, a previous study observed lower prog/e3 among only those without premature rupture of membranes [46], possibly implicating different endocrine pathways in the occurrence of PTB with and without premature rupture of membranes.

Decreased odds of PTB have been shown with increased concentrations of fT4 in the second [20] and third [47] trimesters, which contradicts our finding that fT4 was positively associated with younger gestational age at birth (among the whole study population and when the fetus was male) and increased odds of PTB (when the fetus was male) and spontaneous PTB. One prior study also found increased odds of PTB with increased T3 concentrations at 10 and 26 weeks gestation [47]. Similarly, we found that T3 was associated with spontaneous PTB when the fetus was male. Mechanisms of the association between thyroid hormones and PTB are poorly understood, but previous research has suggested that altered thyroid hormone concentrations may be involved in other disease states or exposures for which we have evidence of associations with PTB such as oxidative stress and inflammation [48-50], or environmental exposures such as phthalates [51-53].

Several previous studies have observed that male fetal sex is associated with a greater risk of delivering preterm. Proposed biological explanations for this observation include a pro-inflammatory environment generated by a male fetus [54] and larger size at birth for males relative to females [55]. Increased risk of PTB when the fetus was male among only Caucasian women has also been observed, suggesting a potential interaction between race and fetal sex [56]. We observed significant associations with PTB unique to women carrying a male fetus for $\mathrm{CRH}$, estriol, progesterone, fT4, and testosterone, providing further evidence that the effect of fetal sex on the occurrence of PTB is important and complex, possibly involving diverse endocrine pathways. 


\section{Preeclampsia}

Women with preeclampsia had lower progesterone and estriol concentrations over the study period than women with normal pregnancies, but only when the fetus was female. We also observed increased odds of preeclampsia to be associated with higher prog/e3, but this relationship was not fetal sex-specific. In accordance with our findings, other studies have shown that progesterone concentrations in the third trimester (29-40 weeks gestation) [21] and estriol concentrations in the second trimester [57] were lower among women with preeclampsia than women with normal pregnancies. Carrying a female fetus has previously been demonstrated as an independent risk factor for developing preeclampsia [58, 59]. Our findings suggest that lower estriol and progesterone concentrations may mediate the association between fetal sex and preeclampsia.

Previous studies have found increased odds of preeclampsia with higher second trimester fT4 concentrations [20,60], and lower third trimester fT4 concentrations [61]. All associations we observed between fT4 and preeclampsia were inverse, although not statistically significant. The association between fT4 and preeclampsia has also been shown to be modified by hCG concentrations, with high fT4 positively associated with preeclampsia only when hCG is low [62]. This effect modification may be due to the known angiogenic role of hCG during early pregnancy [63].

Hormonal involvement in the etiology of preeclampsia is complex due to the angiogenic dysfunction of the affected uterus. In preeclampsia cases, proper remodeling and infiltration of blood vessels by placental extravillous trophoblasts does not occur, and this can be observed before the onset of clinical symptoms $[64,65]$. It is unclear whether endocrine disruption plays a causal role in initiation of uterine dysfunction, or if uterine dysfunction triggers a maternal endocrine response in an attempt to adapt to the hypoxic state [66].

\section{Gestational Diabetes Mellitus}

A previous epidemiology study has demonstrated associations between high second trimester estriol concentrations and greater odds of GDM [22]. We also observed increased odds of GDM with estriol later in pregnancy (around 26 weeks). Testosterone concentrations were inversely associated with odds of GDM in our study, which differs from previous research that showed higher testosterone concentrations among women with GDM [23] and with greater insulin resistance [67] compared to women with normal pregnancies.

Previous work has suggested that fT4 concentrations early in pregnancy are inversely associated with odds of GDM [61, 68]. In accordance with those findings, the ratio of fT3 to fT4 has been observed to be positively associated with odds of GDM [69], suggesting that increased conversion of T4 to biologically active T3 may play a role in the onset of GDM. In alignment with those findings, we observed greater odds of GDM with increased T3 concentrations early in pregnancy (around 18 weeks). Although not statistically significant, we also observed an inverse association between fT4 and odds of GDM at 18 weeks' gestation, while that association reversed at 26 weeks. Previous work has shown that women with GDM have higher circulating concentrations of inflammatory cytokines such as IL-6 and TNF-alpha [70], which have been observed to be inversely associated with T3 concentrations [71]. These inflammatory markers may increase insulin resistance during pregnancy and, mediated by alterations in thyroid hormone concentrations, contribute to higher circulating glucose levels and increased odds of GDM. We also observed gestational average concentrations of fT4 to be positively associated with odds of GDM when the fetus was male, and inversely associated (although not significant) when the fetus was female. Several previous studies have observed greater risks for GDM among women carrying a male fetus [72-74], possibly due to poorer beta-cell function among male fetuses [75].

\section{Birth Size}

We observed that decreased birth weight among females was associated with increasing pregnancy average concentrations of total T4, but not fT4. Previous work found similar inverse associations, but with fT4 instead of total T4 [76, 77]. Thyroid hormones are critical for fetal growth, possibly via their influences on fetal insulin-like growth factor, leptin, or the placenta's abilities to transfer nutrients [78]. Even in the case of nearly identical patterns of thyroid hormone concentrations throughout gestation between mothers, differences in expression of hormone transporters in the placenta and intracellular receptors in fetal tissues can result in different thyroid hormone exposure profiles for the fetus and, consequently, varying effects on fetal growth and development [79]. Assessment of thyroid hormone effects on birth outcomes in the second half of gestation is even more

Page $12 / 20$ 
complex as the fetal thyroid gland begins to produce hormones and the fetus relies less on maternal supply of fT4 [79]. Conflicting results on the relationship between thyroid hormones and birth weight between studies may be due in part to unmeasured differences in fetal thyroid function.

\section{Strengths and Limitations}

The present study was subject to several limitations. We were not able to measure hCG or assess thyroid autoantibody status. Thus some of our results, particularly those involving thyroid hormones and preeclampsia, could be biased due to unmeasured confounding variables. Some critical changes in the maternal endocrine environment occur later in gestation than we were able to measure, such as the exponential increase in $\mathrm{CRH}$ right before the onset of labor. Although the goal of this study was to determine whether mid-pregnancy hormone levels were indicative of increased risk of adverse pregnancy outcomes, measurements at later time points could shed additional light on the various endocrine pathways implicated in adverse birth outcomes. We observed low rates of preeclampsia and GDM, which reduces the reliability of effect estimates. However, these lower rates were observed because we excluded women with preexisting conditions from our cohort to allow more precise examination of associations between hormone concentrations and birth outcomes, since preexisting conditions can influence hormone concentrations and susceptibility to adverse birth outcomes. Furthermore, excluding women with preexisting conditions may limit the generalizability of our findings. Finally, some results assessing preeclampsia and GDM may be subject to reverse causation bias if the disease state, before clinical observation, resulted in the hormonal changes that we observed.

Despite the aforementioned limitations, this study was also strong in various ways. This is one of few studies to assess a broad panel of hormone concentrations at more than one time point during gestation to investigate relationships with various birth outcomes. Many epidemiological studies limit their analytical panel to either thyroid or steroid hormones, or do not assess the spontaneous subtype of PTB. We are also one of few groups to assess interactions between gestational hormone concentrations and fetal sex and gestational age at hormone measurement, which is critical because of known changes in the maternal-fetal endocrine interface throughout gestation and differences related to male and female fetuses. Finally, our study was strengthened by a higher sample size of mothers than was seen in most previously published cohorts, which is particularly important when studying rare outcomes occurring in less than $5 \%$ of the population.

\section{Conclusion}

In conclusion, we observed a range of associations between hormones and adverse birth outcomes. We found differences based on the timing of hormone assessment, and many significant findings were unique to mothers carrying a male fetus. Future work will attempt to place these findings in the context of relevant environmental contaminants on the island of Puerto Rico by exploring possibilities of endocrine disruption as a mediator between chemical exposures and pregnancy outcomes. Additional studies are needed to more fully elucidate the role of altered hormone concentrations in the etiology of adverse birth outcomes.

\section{Abbreviations}

\section{PROTECT}

Puerto Rico Testsite for Exploring Contamination Threats; CRH:corticotropin releasing hormone; E3:estriol; Prog:progesterone; SHBG:sex hormone binding globulin; TSH:thyroid stimulating hormone; T3:triiodothyronine; fT4:free thyroxine; T4:thyroxine; PTB:preterm birth; GDM:gestational diabetes mellitus; SGA:small for gestational age; LGA:large for gestational age; CLASS:Central Ligand Assay Satellite Services; LOD:limit of detection; ICC:intraclass correlation coefficient; IQR:interquartile range; BMl:body mass index.

\section{Declarations}

\section{Ethics approval}

This study was approved by the research and ethics committees of the University of Michigan School of Public Health, University of Puerto Rico, Northeastern University, and participating hospitals and clinics. 


\section{Consent for publication}

All study participants provided full informed consent prior to participation.

\section{Data Availability}

Data and code utilized for this analysis can be obtained by reasonable request by contacting both the first author and corresponding author.

\section{Competing Interests}

The authors have competing interests to disclose.

\section{Funding}

This study was supported by the Superfund Research Program of the National Institute of Environmental Health Sciences (NIEHS), National Institutes of Health (NIH; grant number P42ES017198). Additional support was provided from NIEHS grant number P30ES017885 and the Environmental influences on Child Health Outcomes (ECHO) program grant number $\mathrm{UH} 30 \mathrm{D} 023251$. ECHO is a nationwide research program supported by the $\mathrm{NIH}$, Office of the Director to enhance child health.

\section{Author Contributions}

ALC drafted the manuscript and conducted statistical analyses. CMVV, ANA, JFC, RLC, and JDM made substantial contributions to the conception and design of this work. DJW and ZYR were involved with data acquisition and management. JDM and BM assisted ALC in interpretation of results and statistical planning. All authors were involved with substantial revisions and interpretation of final results, and approved the final submitted version of the manuscript.

\section{Acknowledgements}

We would like to extend our gratitude to all PROTECT study participants and their families. The authors also thank the nurses and research staff who participated in cohort recruitment and follow up, as well as the Federally Qualified Health Centers (FQHC) in Puerto Rico that facilitated participant recruitment, including Morovis Community Health Center, Prymed in Ciales, Camuy Health Services, Inc. and the Delta OBGyn Group in Manati, as well as the Manati Medical Center and the Metro Pavia Hospital in Arecibo.

\section{References}

1. Vogel JP, Chawanpaiboon S, Moller A-B, Watananirun K, Bonet M, Lumbiganon P. The global epidemiology of preterm birth. Best Pract Res Clin Obstet Gynaecol Netherlands. 2018;52:3-12.

2. Blencowe H, Cousens S, Oestergaard MZ, Chou D, Moller A-B, Narwal R, et al. National, regional, and worldwide estimates of preterm birth rates in the year 2010 with time trends since 1990 for selected countries: a systematic analysis and implications. Lancet (London, England). England; 2012;379:2162-72.

3. Luyckx VA. Preterm Birth and its Impact on Renal Health. Semin Nephrol United States. 2017;37:311-9.

4. Leung MP, Thompson B, Black J, Dai S, Alsweiler JM. The effects of preterm birth on visual development. Clin Exp Optom Australia. 2018;101:4-12.

5. Spittle AJ, Morgan C, Olsen JE, Novak I, Cheong JLY. Early Diagnosis and Treatment of Cerebral Palsy in Children with a History of Preterm Birth. Clin Perinatol United States. 2018;45:409-20.

6. Schubert U, Muller M, Abdul-Khaliq H, Norman M. Preterm Birth Is Associated with Altered Myocardial Function in Infancy. J Am Soc Echocardiogr United States. 2016;29:670-8.

7. Nahum Sacks K, Friger M, Shoham-Vardi I, Spiegel E, Sergienko R, Landau D, et al. Prenatal exposure to preeclampsia as an independent risk factor for long-term cardiovascular morbidity of the offspring. Pregnancy Hypertens Netherlands.

2018;13:181-6. 
8. Walker CK, Krakowiak P, Baker A, Hansen RL, Ozonoff S, Hertz-Picciotto I. Preeclampsia, placental insufficiency, and autism spectrum disorder or developmental delay. JAMA Pediatr United States. 2015;169:154-62.

9. Khashan AS, Evans M, Kublickas M, McCarthy FP, Kenny LC, Stenvinkel P, et al. Preeclampsia and risk of end stage kidney disease: A Swedish nationwide cohort study. PLoS Med United States. 2019;16:e1002875.

10. Park Y, Cho GJ, Kim LY, Lee TS, Oh MJ, Kim YH. Preeclampsia Increases the Incidence of Postpartum Cerebrovascular Disease in Korean Population. J Korean Med Sci Korea (South). 2018;33:e35.

11. Zhang C, Olsen SF, Hinkle SN, Gore-Langton RE, Vaag A, Grunnet LG, et al. Diabetes \& Women's Health (DWH) Study: an observational study of long-term health consequences of gestational diabetes, their determinants and underlying mechanisms in the USA and Denmark. BMJ Open England. 2019;9:e025517.

12. Sykes L, Bennett PR. Efficacy of progesterone for prevention of preterm birth. Best Pract Res Clin Obstet Gynaecol Netherlands. 2018;52:126-36.

13. Weiss G. Endocrinology of parturition. J Clin Endocrinol Metab United States. 2000;85:4421-5.

14. Mannisto T, Mendola P, Grewal J, Xie Y, Chen Z, Laughon SK. Thyroid diseases and adverse pregnancy outcomes in a contemporary US cohort. J Clin Endocrinol Metab United States. 2013;98:2725-33.

15. Allan WC, Haddow JE, Palomaki GE, Williams JR, Mitchell ML, Hermos RJ, et al. Maternal thyroid deficiency and pregnancy complications: implications for population screening. J Med Screen England. 2000;7:127-30.

16. Abalovich M, Gutierrez S, Alcaraz G, Maccallini G, Garcia A, Levalle O. Overt and subclinical hypothyroidism complicating pregnancy. Thyroid United States. 2002;12:63-8.

17. Nazarpour S, Ramezani Tehrani F, Simbar M, Azizi F. Thyroid dysfunction and pregnancy outcomes. Iran J Reprod Med Iran. 2015;13:387-96.

18. Feng T, Allen JC, Ng MJ, Yeo GSH, Kwek KYC, Chern BSM, et al. The association between serum progesterone level and preterm delivery. Int J Gynaecol Obstet United States. 2018;142:308-14.

19. Ruiz RJ, Saade GR, Brown CEL, Nelson-Becker C, Tan A, Bishop S, et al. The effect of acculturation on progesterone/estriol ratios and preterm birth in hispanics. Obstet Gynecol. 2008;111:309-16.

20. Korevaar TIM, Chaker L, Medici M, de Rijke YB, Jaddoe VWV, Steegers EAP, et al. Maternal total T4 during the first half of pregnancy: physiologic aspects and the risk of adverse outcomes in comparison with free T4. Clin Endocrinol (Oxf) England. 2016;85:757-63.

21. Shin YY, Jeong JS, Park M-N, Lee J-E, An S-M, Cho W-S, et al. Regulation of steroid hormones in the placenta and serum of women with preeclampsia. Mol Med Rep Greece. 2018;17:2681-8.

22. Hur J, Cho E-H, Baek K-H, Lee KJ. Prediction of Gestational Diabetes Mellitus by Unconjugated Estriol Levels in Maternal Serum. Int J Med Sci Australia. 2017;14:123-7.

23. Gozukara YM, Aytan H, Ertunc D, Tok EC, Demirturk F, Sahin S, et al. Role of first trimester total testosterone in prediction of subsequent gestational diabetes mellitus. J Obstet Gynaecol Res Australia. 2015;41:193-8.

24. Meeker JD, Cantonwine DE, Rivera-Gonzalez LO, Ferguson KK, Mukherjee B, Calafat AM, et al. Distribution, variability, and predictors of urinary concentrations of phenols and parabens among pregnant women in Puerto Rico. Environ Sci Technol United States. 2013;47:3439-47.

25. Meeker JD, Cantonwine DE, Rivera-Gonz??lez LO, Ferguson KK, Mukherjee B, Calafat AM, et al. Distribution, variability, and predictors of urinary concentrations of phenols and parabens among pregnant women in puerto rico. Environ Sci Technol. 2013;47:3439-47.

26. RRID:AB_2783800.

27. RRID:AB_2783801.

28. RRID:AB_2783804.

29. RRID:AB_2783802.

30. RRID:AB_2783803.

31. RRID:AB_2783805.

Page 15/20 
32. RRID:AB_2783806.

33. RRID:AB_2783799.

34. RRID:AB_2783798.

35. Dietrich JW, Landgrafe G, Fotiadou EH. TSH and thyrotropic agonists: Key actors in thyroid homeostasis. J Thyroid Res. 2012;2012.

36. Romero R, Scoccia B, Mazor M, Wu YK, Benveniste R. Evidence for a local change in the progesterone/ estrogen ratio in human parturition at term. Am J Obstet Gynecol [Internet]. 1988;159:657-60. Available from:

http://www.sciencedirect.com/science/article/pii/S0002937888800292.

37. Pettker C, Goldberg J, El-Sayed Y, Copel J. Committee Opinion No 700: Methods for Estimating the Due Date. Obstet Gynecol United States. 2017;129:e150-4.

38. McElrath TF, Hecht JL, Dammann O, Boggess K, Onderdonk A, Markenson G, et al. Pregnancy disorders that lead to delivery before the 28th week of gestation: an epidemiologic approach to classification. Am J Epidemiol. 2008;168:980-9.

39. Villar J, Cheikh Ismail L, Victora CG, Ohuma EO, Bertino E, Altman DG, et al. International standards for newborn weight, length, and head circumference by gestational age and sex: the Newborn Cross-Sectional Study of the INTERGROWTH-21st Project. Lancet (London, England). England; 2014;384:857-68.

40. Carlo Di Renzo G, Giardina I, Clerici G, Brillo E, Gerli S. Progesterone in normal and pathological pregnancy. Horm Mol Biol Clin Investig. 2016;27:35-48.

41. 10.1016/j.jsbmb.2013.01.015

Byrns MC. Regulation of progesterone signaling during pregnancy: Implications for the use of progestins for the prevention of preterm birth. J Steroid Biochem Mol Biol [Internet]. Elsevier Ltd; 2014;139:173-81. Available from: http://dx.doi.org/10.1016/j.jsbmb.2013.01.015.

42. Mesiano S, Welsh TN. Steroid hormone control of myometrial contractility and parturition. Semin Cell Dev Biol. 2007;18:321-31.

43. Snegovskikh V, Park JS. Endocrinology of Parturition. Endocrinol Metab Clin North Am. 2006;35:173-91.

44. Challis JRG, Matthews SG, Gibb W, Lye SJ. C DPJRG. Endocrine and Paracrine Regulation of Birth at Term and Preterm. Endocr Rev. 2000;21:514-50.

45. Moran D, Mcgarrigle HH, Lachelin GC. Lack of normal increase in saliva estriol / progesterone ratio in women with labor induced at 42 weeks ' gestation. Am J Obstet Gynecol. 1983;167.

46. Darne J, Mcgarrigle H, Lachelin G. Increased saliva oestriol to progesterone ratio before idiopathic preterm delivery: a possible predictor for preterm labour? Br Med J. 1987;294:270-2.

47. Johns LE, Ferguson KK, McElrath TF, Mukherjee B, Seely EW, Meeker JD. Longitudinal profiles of thyroid hormone parameters in pregnancy and associations with preterm birth. PLoS One. 2017;12:1-15.

48. Mancini A, Di Segni C, Raimondo S, Olivieri G, Silvestrini A, Meucci E, et al. Thyroid Hormones, Oxidative Stress, and Inflammation. Mediators Inflamm United States. 2016;2016:6757154.

49. Moore TA, Ahmad IM, Zimmerman MC. Oxidative Stress and Preterm Birth: An Integrative Review. Biol Res Nurs United States. 2018;20:497-512.

50. Cappelletti M, Della Bella S, Ferrazzi E, Mavilio D, Divanovic S. Inflammation and preterm birth. J Leukoc Biol United States. 2016;99:67-78.

51. Cathey AL, Watkins D, Rosario ZY, Velez C, Alshawabkeh AN, Cordero JF, et al. Associations of Phthalates and Phthalate Replacements With $\mathrm{CRH}$ and Other Hormones Among Pregnant Women in Puerto Rico. J Endocr Soc United States. 2019;3:1127-49.

52. Johns LE, Ferguson KK, McElrath TF, Mukherjee B, Meeker JD. Associations between Repeated Measures of Maternal Urinary Phthalate Metabolites and Thyroid Hormone Parameters during Pregnancy. Environ Health Perspect United States.

2016;124:1808-15.

Page 16/20 
53. Ferguson KK, Rosen EM, Rosario Z, Feric Z, Calafat AM, McElrath TF, et al. Environmental phthalate exposure and preterm birth in the PROTECT birth cohort. Environ Int Netherlands. 2019;132:105099.

54. Challis J, Newnham J, Petraglia F, Yeganegi M, Bocking A. Fetal sex and preterm birth. Placenta Netherlands. 2013;34:95-9.

55. McGregor JA, Leff M, Orleans M, Baron A. Fetal gender differences in preterm birth: findings in a North American cohort. Am J Perinatol United States. 1992;9:43-8.

56. Wilms FF, Vis JY, Oudijk MA, Kwee A, Porath MM, Scheepers HCJ, et al. The impact of fetal gender and ethnicity on the risk of spontaneous preterm delivery in women with symptoms of preterm labor. J Matern Fetal Neonatal Med England. 2016;29:3563-9.

57. Tache V, Baer RJ, Currier RJ, Li C-S, Towner D, Waetjen LE, et al. Population-based biomarker screening and the development of severe preeclampsia in California. Am. J. Obstet. Gynecol. United States; 2014 Oct.

58. Zheng Q, Deng Y, Zhong S, Shi Y. Human chorionic gonadotropin, fetal sex and risk of hypertensive disorders of pregnancy: A nested case-control study. Pregnancy Hypertens Netherlands. 2016;6:17-21.

59. Shiozaki A, Matsuda Y, Satoh S, Saito S. Impact of fetal sex in pregnancy-induced hypertension and preeclampsia in Japan. J Reprod Immunol Ireland. 2011;89:133-9.

60. Medici M, Korevaar TIM, Schalekamp-Timmermans S, Gaillard R, de Rijke YB, Visser WE, et al. Maternal early-pregnancy thyroid function is associated with subsequent hypertensive disorders of pregnancy: the generation R study. J Clin Endocrinol Metab United States. 2014;99:E2591-8.

61. Zhang Y, Dai X, Yang S, Zhang C, Han M, Huang H-F, et al. Maternal low thyroxin levels are associated with adverse pregnancy outcomes in a Chinese population. PLoS One United States. 2017;12:e0178100.

62. Korevaar TIM, Steegers EAP, Chaker L, Medici M, Jaddoe VWV, Visser TJ, et al. The Risk of Preeclampsia According to High Thyroid Function in Pregnancy Differs by hCG Concentration. J Clin Endocrinol Metab United States. 2016;101:5037-43.

63. Barjaktarovic M, Korevaar TIM, Jaddoe VWV, de Rijke YB, Peeters RP, Steegers EAP. Human chorionic gonadotropin and risk of pre-eclampsia: prospective population-based cohort study. Ultrasound Obstet Gynecol England. 2019;54:477-83.

64. Lala PK, Chakraborty C. Factors regulating trophoblast migration and invasiveness: possible derangements contributing to pre-eclampsia and fetal injury. Placenta Netherlands. 2003;24:575-87.

65. Roberts DJ, Post MD. The placenta in pre-eclampsia and intrauterine growth restriction. J Clin Pathol England. 2008;61:1254-60.

66. Boeldt DS, Bird IM. Vascular adaptation in pregnancy and endothelial dysfunction in preeclampsia. J Endocrinol England. 2017;232:R27-44.

67. Morisset A-S, Dube M-C, Drolet R, Pelletier M, Labrie F, Luu-The V, et al. Androgens in the maternal and fetal circulation: association with insulin resistance. J Matern Fetal Neonatal Med England. 2013;26:513-9.

68. Yang S, Shi F-T, Leung PCK, Huang H-F, Fan J. Low Thyroid Hormone in Early Pregnancy Is Associated With an Increased Risk of Gestational Diabetes Mellitus. J Clin Endocrinol Metab United States. 2016;101:4237-43.

69. Rawal S, Tsai MY, Hinkle SN, Zhu Y, Bao W, Lin Y, et al. A Longitudinal Study of Thyroid Markers Across Pregnancy and the Risk of Gestational Diabetes. J Clin Endocrinol Metab United States. 2018;103:2447-56.

70. Ategbo J-M, Grissa O, Yessoufou A, Hichami A, Dramane KL, Moutairou K, et al. Modulation of adipokines and cytokines in gestational diabetes and macrosomia. J Clin Endocrinol Metab United States. 2006;91:4137-43.

71. Boelen A, Platvoet-Ter Schiphorst MC, Wiersinga WM. Association between serum interleukin-6 and serum 3,5,3'triiodothyronine in nonthyroidal illness. J Clin Endocrinol Metab United States. 1993;77:1695-9.

72. Verburg PE, Tucker G, Scheil W, Erwich JJHM, Dekker GA, Roberts CT. Sexual Dimorphism in Adverse Pregnancy Outcomes A Retrospective Australian Population Study 1981-2011. PLoS One United States. 2016;11:e0158807.

73. Retnakaran R, Shah BR. Fetal Sex and the Natural History of Maternal Risk of Diabetes During and After Pregnancy. J Clin Endocrinol Metab United States. 2015;100:2574-80.

74. Sheiner E, Levy A, Katz M, Hershkovitz R, Leron E, Mazor M. Gender does matter in perinatal medicine. Fetal Diagn Ther Switzerland. 2004;19:366-9.

Page $17 / 20$ 
75. Retnakaran R, Kramer CK, Ye C, Kew S, Hanley AJ, Connelly PW, et al. Fetal sex and maternal risk of gestational diabetes mellitus: the impact of having a boy. Diabetes Care United States. 2015;38:844-51.

76. Johns LE, Ferguson KK, Cantonwine DE, Mukherjee B, Meeker JD, McElrath TF. Subclinical Changes in Maternal Thyroid Function Parameters in Pregnancy and Fetal Growth. J Clin Endocrinol Metab United States. 2018;103:1349-58.

77. Leon G, Murcia M, Rebagliato M, Alvarez-Pedrerol M, Castilla AM, Basterrechea $M$, et al. Maternal thyroid dysfunction during gestation, preterm delivery, and birthweight. The Infancia y Medio Ambiente Cohort, Spain. Paediatr Perinat Epidemiol England. 2015;29:113-22.

78. Sferruzzi-Perri AN, Vaughan OR, Forhead AJ, Fowden AL. Hormonal and nutritional drivers of intrauterine growth. Curr Opin Clin Nutr Metab Care England. 2013;16:298-309.

79. Forhead AJ, Fowden AL. Thyroid hormones in fetal growth and prepartum maturation. J Endocrinol England. 2014;221:R87-103.

\section{Figures}
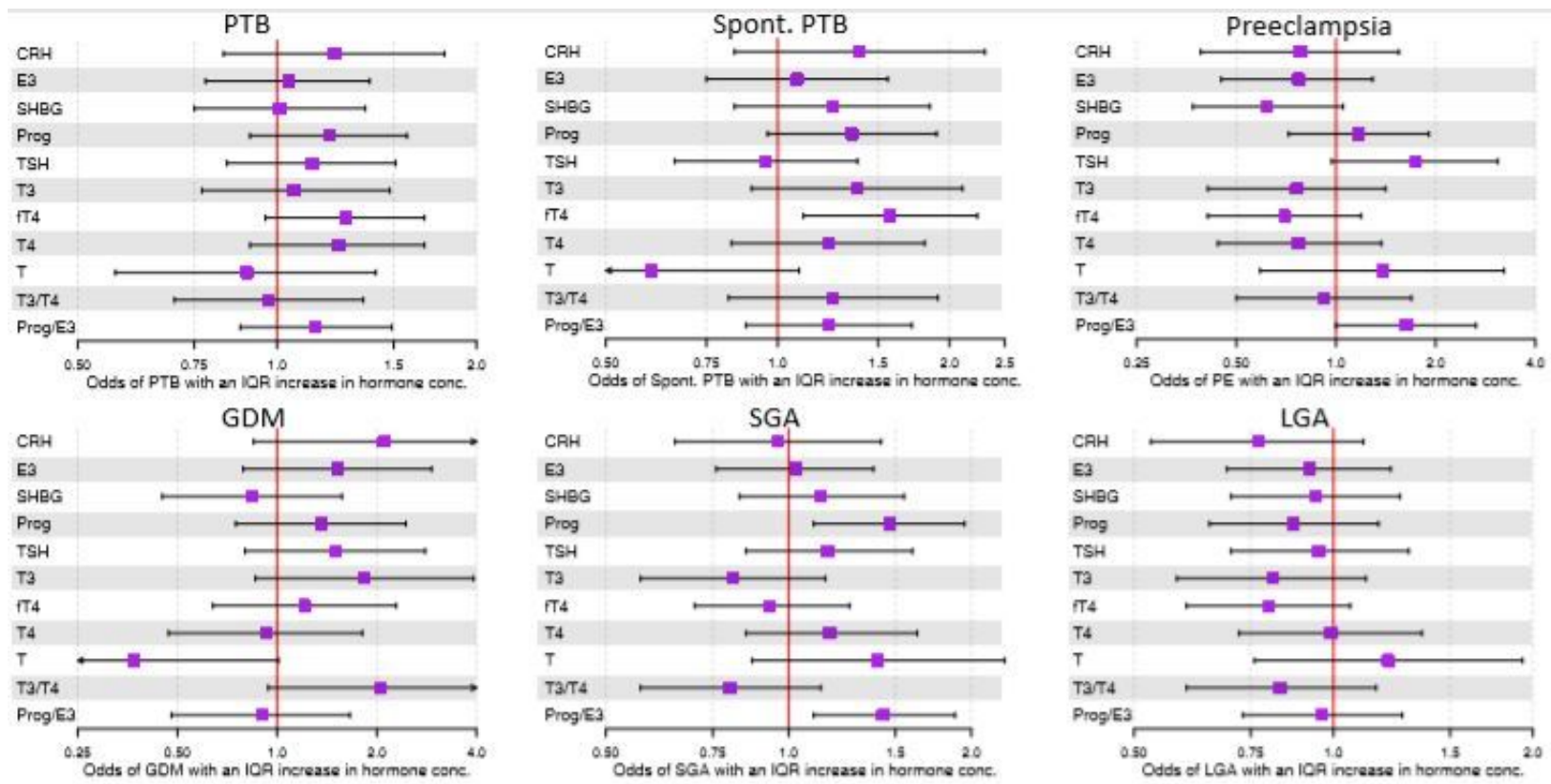

Gestational Age at Birth

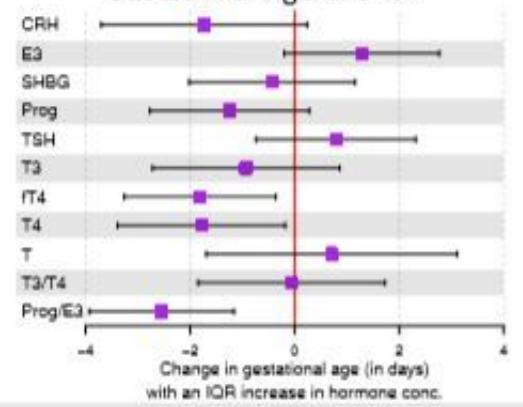

Birth Weight

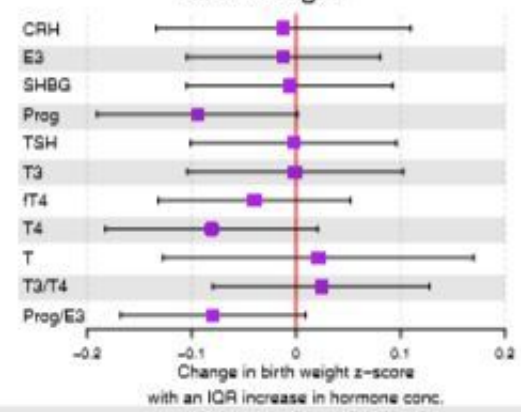

Figure 1

Associations between gestational average hormone concentrations and birth outcomes among all women in the study. Purple boxes represent the effect estimates and black bars represent the $95 \%$ confidence interval. The vertical red line represents the null value. 

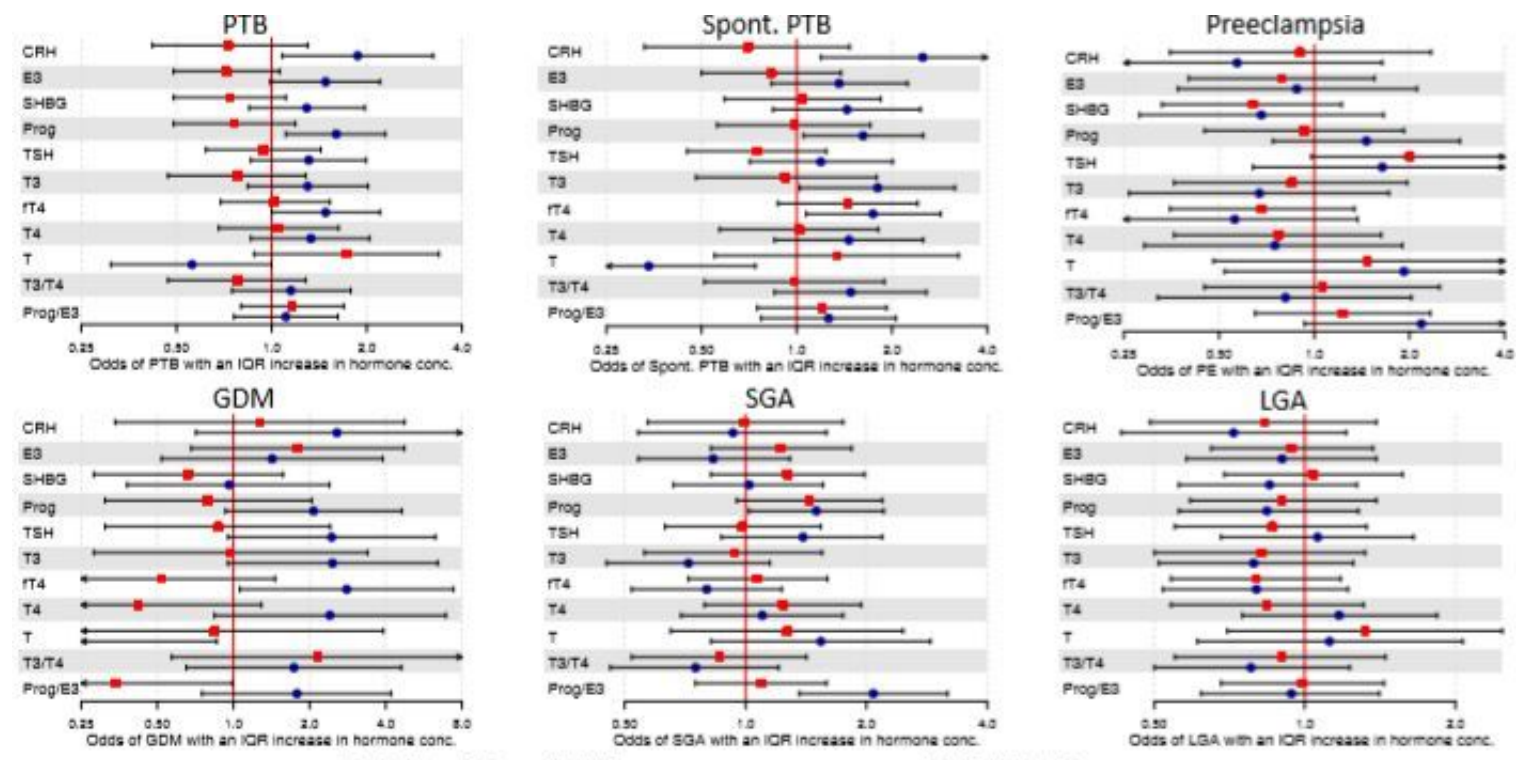
Gestational Age at Birth

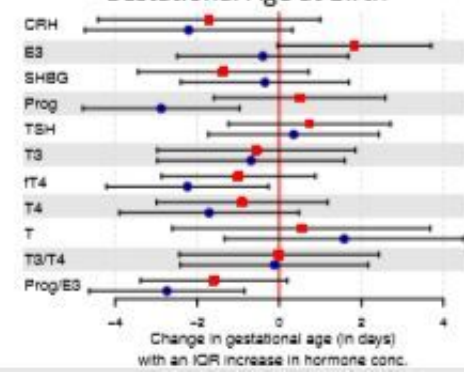

Birth Weight

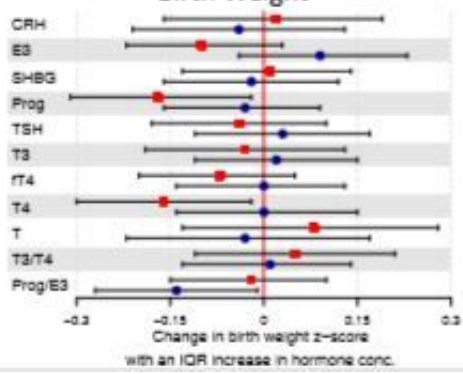

afemales

-Males

Figure 2

Hormones are differentially associated with birth outcomes when fetal sex is female versus male. Red boxes represent the effect estimates for female fetal sex, blue circles represent the effect estimates for male fetal sex, and black bars represent the $95 \%$ confidence interval. The vertical red line represents the null value. 

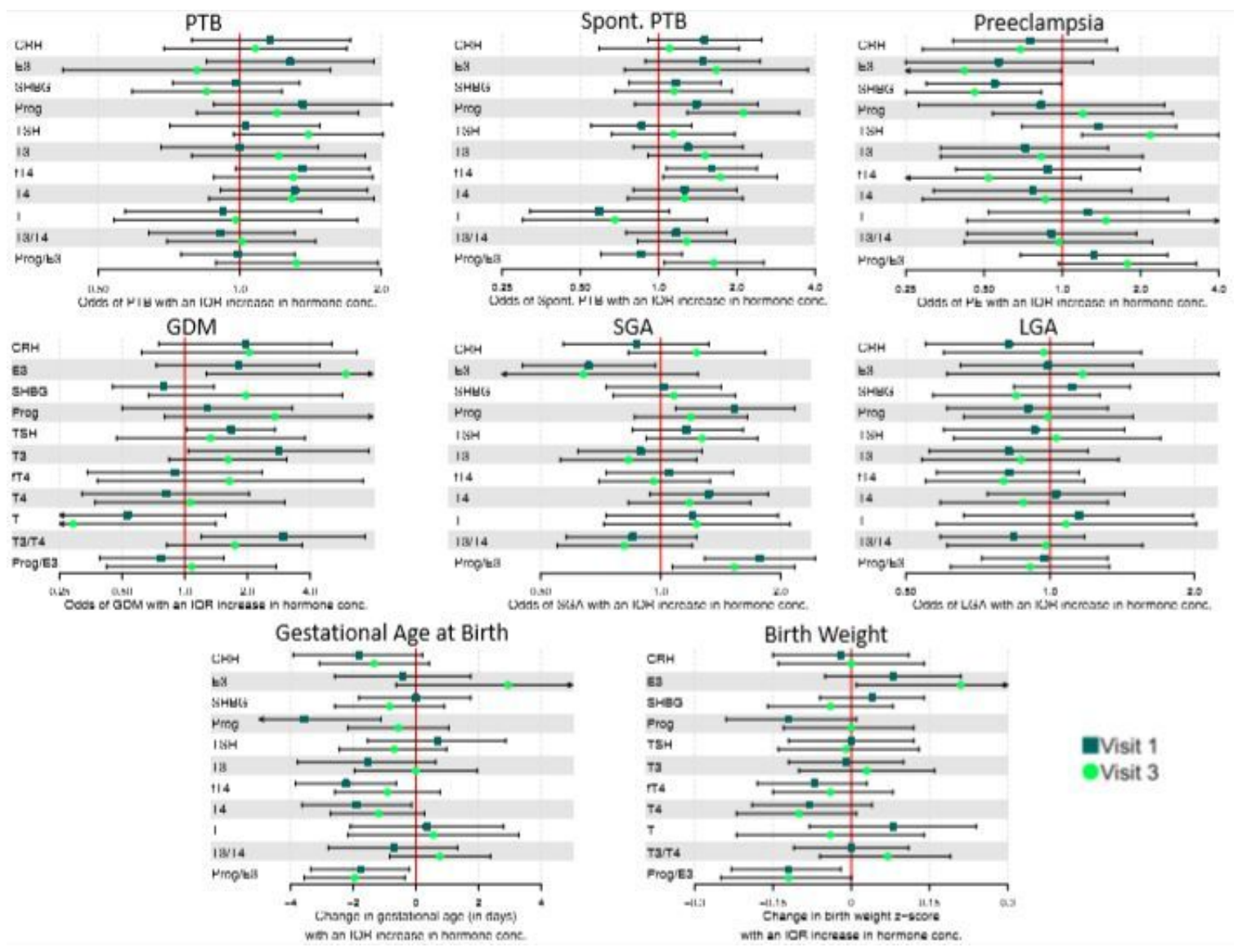

Visit 1

Visit 3

\section{Figure 3}

Associations between hormone concentrations measured at two different time points during gestation and birth outcomes. Dark green boxes represent the effect estimates for hormones measured around 18 weeks, light green circles represent the effect estimates for hormones measured around 26 weeks, and black bars represent the $95 \%$ confidence interval. The vertical red line represents the null value.

\section{Supplementary Files}

This is a list of supplementary files associated with this preprint. Click to download.

- STROBEReprodHealth.docx

- FigureS1HormonesandBirth.pdf 